\title{
Sobre os livros: as perspectivas de Michel de Montaigne, Walter Benjamin e Theodor Adorno ${ }^{1}$
}

\author{
About books: the perspectives of Michel de Montaigne, Walter Benjamin and \\ Theodor Adorno
}

Carlos Eduardo Oliva de C. Rego ${ }^{2}$; Maíra Aparecida Reis Costa ${ }^{3}$

\begin{abstract}
RESUMO: Relatamos uma pesquisa - cuja metodologia se apoiou em revisão bibliográfica empreendida por dois professores da educação básica, refletindo uma prática pedagógica de estímulo à relação dos alunos com livros, em que buscamos ensaios sobre os livros como objeto de análise e sua relação com nossas subjetividades, desde o ensaio cético de Michel de Montaigne intitulado Dos Livros até os ensaios críticos intitulados Desempacotando Minha Biblioteca e Caprichos Bibliográficos, respectivamente, de Walter Benjamin e Theodor Adorno. Pretendemos, com este relato, abordar como os livros foram interpretados em tais perspectivas cética e crítica, sugerindo sua importância para a subjetividade humana, em um momento em que as novas tecnologias de informação e comunicação parecem tão centrais no debate sobre a sociedade e suas expectativas respeitantes à educação de crianças e jovens. Para nós, cabe, neste momento, reavaliarmos recursos como os livros e sua importância para apoio cognitivo e emocional dos alunos. Como resultados da investigação, chegamos às conclusões de que há em Montaigne um elogio à liberdade de pensamento e julgamento, com os livros aparecendo como meio de aquisição de conhecimento e de ampliação da nossa capacidade de pensar e analisar diferentes fenômenos; de que Benjamin realiza uma defesa apaixonada de uma relação subjetiva com os livros, que dá suporte emocional a seu colecionador e de que Adorno nos permite refletir o quanto os livros podem nos humanizar, havendo neles potencial da descoberta da humanidade ali contida, para além de sua abordagem como mercadoria.
\end{abstract}

PALAVRAS-CHAVE: Livros, Michel de Montaigne, Crítica

ABSTRACT: We report a research, whose methodology was supported by bibliographic review, done by two teachers of basic education, reflecting a pedagogical practice of stimulating the relationship of students with books, in which we seek essays on books as an object of analysis and their relationship with our subjectivities, since the skeptical essay by Michel de Montaigne entitled From the books to the critical essays entitled Unpacking My Library and Bibliographical stubbornness, respectively, by Walter Benjamin and Theodor Adorno. We intend, with this report,

${ }^{1} \mathrm{O}$ presente artigo se trata de versão modificada de trabalho apresentado no XI Simpósio Educação e Sociedade Contemporânea: desafios e propostas - Viver é Aprender: educadores e espaços de experimentação, resistência e superação (XI SESC), em 2020, realizado pelo Colégio de Aplicação da Universidade do Estado do Rio de Janeiro (CAp-UERJ).

${ }^{2}$ Professor do Colégio Pedro II - Campus Centro. Pesquisador do Laboratório de Educação em Direitos Humanos LAEDH/CPII. Doutor e mestre em Ciência Política pela Universidade Federal Fluminense e bacharel e licenciado em Ciências Sociais pela Universidade Federal do Rio de Janeiro. ORCID: https://orcid.org/0000-0001-6299-7350. Email: caduardoliva@gmail.com

${ }^{3}$ Professora da Secretaria de Estado de Educação de Minas Gerais. Mestre em Educação e licenciada em Letras pela Universidade Federal de Alfenas. ORCID: https://orcid.org/0000-0002-4785-3866. E-mail: mairapreisc@ gmail.com 
to approach how the books were interpreted in such skeptical and critical perspectives, suggesting their importance for human subjectivity, at a time when new information and communication technologies seem so central in the debate about society and its expectations concerning the education of children and young people. For us, it is now time to reevaluate resources such as books and their importance for students cognitive and emotional support. As a result of the investigation, we came to the conclusion that in Montaigne there is a praise for freedom of thought and judgment, with books appearing as a means of acquiring knowledge and expanding our ability to think and analyze different phenomena; that Benjamin makes a passionate defense of a subjective relationship with books, that gives emotional support to his collector and that Adorno allows us to reflect how much books can humanize us, with the potential for discovering humanity contained therein, distinguishing from his approach as a commodity.

KEYWORDS: Books, Michel de Montaigne, Criticism

\section{INTRODUÇÃO}

Neste artigo, apresentaremos uma reflexão sobre os livros como objeto de análise e sua relação com nossas subjetividades, partindo do ensaio cético de Montaigne (1533-1592) intitulado Dos Livros (Des Libres), décimo capítulo do segundo livro de Os Ensaios (Les Essais) do final do Século XVI, e alcançando os ensaios críticos intitulados Desempacotando Minha Biblioteca (Ich packe meine Bibliothek aus), da primeira metade do Século XX, publicado em Rua de Mão Única (Einbanhstraße), e Caprichos Bibliográficos (Bibliographische Grillen), da segunda metade do Século XX, publicado em Notas de Literatura (Noten zur Literatur), respectivamente de Walter Benjamin (1892-1940) e Theodor Adorno (1903-1969).

Pretendemos, com esta reflexão, abordar como os livros foram interpretados em perspectiva cética e em perspectiva crítica pelos referidos autores, sugerindo toda a sua importância para a subjetividade humana, cujo cultivo se faz pela formação, em um momento em que as novas tecnologias de informação e comunicação parecem tão centrais no debate sobre educação e sua relação com as expectativas da sociedade respeitantes ao percurso formativo das crianças e jovens. Cabe, neste momento de enfrentamento da pandemia de Covid-19, reavaliarmos recursos como os livros e sua importância para o apoio cognitivo e emocional dos seres humanos.

Por fim, destacamos que este trabalho corresponde a um relato de pesquisa, cuja metodologia se apoiou em revisão bibliográfica dos referidos ensaios, empreendida por dois professores da educação básica - um professor de Sociologia do Colégio Pedro II (RJ) e uma professora de Língua Portuguesa da Escola Estadual Coronel João Ferreira Barbosa (MG) - que reflete sua prática pedagógica de estímulo à relação de seus alunos com os livros, inclusive no momento da Pandemia que atravessamos, em uma prática pedagógica, sobre a qual aqui apresentamos fundamentos teóricos. 


\section{REFLEXÕES CÉTICAS SOBRE OS LIVROS EM MONTAIGNE}

Nesta seção, apresentaremos as reflexões de Montaigne (1533-1592), pensador cético do Século XVI, sobre os livros, trazida em seu ensaio Dos Livros (Des Libres), capítulo X do Livro II de seu Os Ensaios (Les Essais). Trata-se de uma fundamentação teórica importante na pesquisa que fizemos, que nos traz uma interessante abordagem acerca da relação que podemos estabelecer com os livros, pensando no estímulo que podemos dar a nossos alunos para que constituam, com os livros, esta relação.

Montaigne (1984), no referido ensaio, parte do princípio de que a ignorância permite ao ser humano perceber que ele é dotado da capacidade de julgamento. Nesse sentido, a liberdade advém da ignorância, uma vez que permite às pessoas a reflexão. Diz o autor: "exprimo livremente minha opinião acerca de tudo, mesmo daquilo que, por ultrapassar meus conhecimentos intelectuais, considero fora de minha alçada. O meu comentário tem por fim revelar meu ponto de vista, e não julgar do mérito das coisas" (MONTAIGNE, 1984, p. 193). A opinião não visa, nessa perspectiva, apontar a qualidade das coisas, mas proporcionar liberdade de escolha, julgamento e reflexão, como propõe o pensamento cético.

Montaigne (1984) ressalta a necessidade de se tratar assuntos com liberdade, sem perda de tempo ou a demanda de muitos esforços. Para ele, é possível adquirir ensinamentos a partir dos livros e a aquisição do conhecimento deve ser feita de maneira tranquila, pois não se deve pagar um preço caro. Interessa a ele desenvolver o conhecimento de si para que possa viver e morrer bem: "não busco nos livros senão o prazer de um honesto passatempo: e nesse estudo não me prendo senão ao que possa desenvolver em mim o conhecimento de mim mesmo e me auxilie a viver e morrer bem" (MONTAIGNE, 1984, p. 192).

Segundo Montaigne (1984), o processo de busca é permanente, pois há sempre outras interpretações, inquietações e possibilidades:

Penso dar uma interpretação justa às aparências que apreendo, mas como são enganosas, imperfeitas! Em sua maioria as fábulas de Esopo apresentam vários sentidos e significações. Os que as interpretam mitologicamente palmilham por certo um terreno bem adequado à fábula: mas é permanecer à superfície: há outra interpretação mais viva, essencial e interior, a que não puderam chegar os eruditos. (MONTAIGNE, 1984, p. 193)

Acerca da relação de Montaigne (1984) com os livros, é ainda possível notar que para ele as leituras "instruem e deleitam ao mesmo tempo", o ensinando a "pensar" e a se conduzir. A partir da leitura é possível que sejam extraídos conhecimentos substanciais e nutritivos. Há, entretanto, no ensaio do autor, uma crítica ao discurso, à eloquência, ao despejar das palavras, que deixam o 
ouvinte sonolento: "lamento o tempo que perde, em vãs interlocuções preparatórias, um homem que tinha tanta coisa importante a dizer" (MONTAIGNE, 1984, p. 195). E Montaigne observa que devemos julgar um autor a partir da leitura de sua obra.

O apreço do filósofo pelos historiadores é notável. Aponta, dessa maneira, que é preciso penetrar e conhecer suas obras, como maneira de valorizar o conhecimento, o estudo e o aprofundamento:

Os historiadores constituem meu passatempo predileto. Sua leitura é-me fácil e agradável. Em seus livros encontro o homem que procuro penetrar e conhecer, apresentado com maior nitidez e mais completamente do que alhures. Sua maneira de ser neles se projeta com mais relevo e verossimilhança, tanto nos pormenores como no conjunto. (MONTAIGNE, 1984, p. 196)

Outro aspecto relevante de seu pensamento diz respeito ao conhecimento de diferentes autores e pontos de vista históricos, literários, filosóficos. Nesse sentido, o cético observa que é preciso folhear inúmeros autores com diferentes pontos de vista sobre os quais cada coisa se apresenta:

Sinto muito não termos uma dúzia de Diógenes Laércio ou que sua obra não seja mais extensa ou mais inteligentemente composta, pois me interesso tanto pela vida dos grandes educadores quando por seus dogmas e suas idéias. Quando nos dedicamos a estudos históricos desse gênero, precisamos folhear inúmeros autores, velhos ou novos, escritos em bom ou mau francês, a fim de conhecermos os diferentes pontos de vista sob os quais cada coisa se apresenta. (MONTAIGNE, 1984, p. 196)

Por fim, Montaigne (1984) destaca que aprecia dois tipos de historiadores: os muito simples ou os excelentes. Os que são simples, especialmente porque recolhem com cuidado e exatidão tudo que chega a seu conhecimento, "sem selecionar, sem nada fazer que possa influir no nosso julgamento, na descoberta da verdade" (MONTAIGNE, 1984, p. 196). Já os perfeitos teriam a inteligência necessária para discernir o que merece passar à eternidade, sendo capazes de distinguir, entre os relatos, o mais verossímil. Para ele, porém, os que ocupam um lugar intermediário estragam tudo porque "querem mastigar os fatos para nós; pretendem julgar e falseiam a história de acordo com o que dela pensam" (MONTAIGNE, 1984, p. 196). Em seguida, antes de encerrar este ensaio, se recorda das anotações feitas após as leituras de grandes obras.

Em suma, notamos que Montaigne faz um elogio à liberdade de pensamento e de julgamento, com a possibilidade dos livros lhe levarem a um autoconhecimento, em um processo de busca permanente de outras interpretações, inquietações e possibilidades. Além disso, defende o conhecimento de diferentes autores e pontos de vista sobre os quais cada coisa se apresenta. Na sua exposição do gosto pelos historiadores simples ou excelentes, evidencia que prefere os historiadores que não interferem em seu julgamento ou que possuem melhor discernimento, mas não quem 
pretende julgar a história de acordo com o que dela pensem. Os livros aparecem, assim, não de forma romântica ou sagrada, mas como meio de aquisição de conhecimento e de ampliação da capacidade humana de pensar e de analisar os mais diferentes fenômenos.

\section{REFLEXÕES CRÍTICAS SOBRE OS LIVROS EM BENJAMIN E ADORNO}

Nesta segunda seção, apresentaremos as reflexões de Walter Benjamin (1892-1940) e Theodor Adorno (1903-1969), pensadores críticos do Século XX, sobre os livros, trazida em seus ensaios Desempacotando Minha Biblioteca (Ich packe meine Bibliothek aus), da primeira metade do Século XX, publicado em Rua de Mão Única (Einbanhstraße) de Benjamin, e Caprichos Bibliográficos (Bibliographische Grillen), da segunda metade do Século XX, publicado em Notas de Literatura (Noten zur Literatur) de Adorno. Ambos constituem também fundamentações teóricas importantes na pesquisa que fizemos, que nos trazem abordagens do Século XX acerca da relação que podemos estabelecer com os livros, pensando, mais uma vez, como dissemos acima, no estímulo que podemos dar a nossos alunos para que constituam, com os livros, esta relação.

\section{OS LIVROS EM DESEMPACOTANDO MINHA BIBLIOTECA DE BENJAMIN}

Em Desempacotando Minha Bibioteca, Benjamin (2009) realiza uma apaixonada palestra sobre o colecionador de livros, que inicia contando que estava a desempacotar a sua biblioteca. Os livros não estão ainda nas prateleiras, mas ele pede que o acompanhemos na desordem de caixas abertas e pilhas de livros que voltam a ver a luz do dia, depois de dois anos de guardados.

Benjamin se declara como um colecionador de livros. E será deste ponto de vista que tratará do tema: "o que me move é dar-vos uma ideia da relação de um coleccionador com as peças da sua colecção, uma perspectiva da actividade de coleccionar, mais do que de uma colecção. Faço-o, de modo arbitrário, reflectindo sobre os diversos modos de adquirir livros" (BENJAMIN, 2009, p. 1). O encantamento do colecionador se dá para com os seus livros, e se todos os livros têm seu destino (conforme a máxima Latina citada por Benjamin, habent sua fata libelli, "os livros têm seu próprio destino"), o colecionador interpreta diferente esta máxima, pois são os exemplares e não as obras que possuem seu próprio destino: o encontro desses exemplares com os colecionadores e suas coleções. Por isso, diz: "não exagero quando digo que para um colecionador a aquisição de um livro antigo significa o seu renascimento" (BENJAMIN, 2009, p. 2). 
Mas Benjamin também trata de como os livros ultrapassam o limiar de uma coleção, com uma história de sua aquisição. E, neste sentido, diz que "de todas as formas de obter livros, a que se considera mais louvável é escrevê-los.” (BENJAMIN, 2009, p. 2) Assim,

Os escritores são de facto pessoas que escrevem livros, não por pobreza, mas por insatisfação com os livros que poderiam comprar, mas não lhes agradam. Direis, minhas senhoras e meus senhores, que se trata de uma definição bizarra do escritor. Mas bizarro é tudo aquilo que se diz a partir do ponto de vista de um autêntico coleccionador. (BENJAMIN, 2009, p. 2)

Já dentre outros modos de aquisição de livros, trata ironicamente do empréstimo sem devolução, o que não significará a leitura das obras, mas sua aquisição:

Entre os modos de aquisição mais correntes, o mais conveniente para o colecionador seria o de os pedir emprestados, sem depois os devolver. Os grandes especialistas em pedir livros emprestados, que estamos a considerar, revela ser um inveterado coleccionador de livros, não tanto pelo fervor com que guarda o seu tesouro emprestado, fazendo orelhas moucas a todas as advertências da legalidade corrente, mas muito mais porque também ele não lê esses livros. (BENJAMIN, 2009, p. 2)

"E isso de não ler os livros", diz Benjamin, não é característica do colecionador, sendo uma das coisas mais velhas do mundo. Benjamin chega a considerar "idiota" a pergunta "E o senhor leu tudo isto?" referindo-se a passagem de recordação de Anatole France.

Benjamin (2009) nos conta que durante anos sua biblioteca crescia muito pouco anualmente, porque neste período nenhum livro podia entrar nela sem que o tivesse lido. Depois, passou a comprar livros como um colecionador, o que tem pouca relação, segundo ele, com a compra que um estudante faz em uma livraria ou alguém que queira presentear outra pessoa ou ainda quem quer ler apenas para encurtar uma viagem. Recorda-se, Benjamin, de compras memoráveis de livros. E define os colecionadores como pessoas com instinto tático: assim que chegam a uma cidade, querem ir aos seus alfarrabistas. Além disso, reflete sobre os livros adquiridos por encomenda:

E ainda que o comprador conheça muito bem o livro que encomenda por catálogo, o exemplar é sempre uma surpresa e na encomenda há sempre uma ponta de acaso. Acontecem, a par de dolorosas desilusões, os achados mais felizes. Lembro-me, por exemplo, de um dia ter encomendado um livro com ilustrações coloridas para a minha colecção de livros infantis antigos, só porque ele continha contos de Albert Ludwig Grimm e tinha sido editado em Grimma, na Turíngia. Precisamente de Grimma procedia um livro de fábulas editado por esse mesmo Albert Ludwig Grimm. E o exemplar que eu possuía, com as suas dezasseis ilustrações, era o único testemunho preservado do grande ilustrador alemão Lyser, que viveu em Hamburgo em meados do século passado. Ora, a minha reacção à coincidência dos nomes fora muito exacta. Também neste livro descobri trabalhos de Lyser, precisamente uma obra - Linas Mãhrchen-buch [O Livro de Contos de Lina] - 
desconhecida de todos os seus bibliógrafos, e que merece uma referência explícita como esta, que é a primeira. (BENJAMIN, 2009, p. 3)

Para Benjamin, ainda, "a compra de livros não se resume a uma questão de dinheiro ou de conhecimento especializado. Nem mesmo as duas coisas juntas bastam para fundar uma biblioteca, que tem sempre, ao mesmo tempo, alguma coisa de misterioso e de inconfundível" (BENJAMIN, 2009, p. 3). Exige-se "faro muito apurado" com "datas, nomes de lugares, formatos, donos anteriores, encadernação, etc" - e tudo isso tem de lhe dizer alguma coisa, chegando ele a lembrar de alguns leilões de livros de que participou e o seu sentimento com o feito. Sobre as recordações trazidas com um desempacotar de livros, diz:

Quantas coisas não voltam à memória quando nos aventuramos na montanha de caixas, para retirar dela os livros no nosso trabalho diurno, ou melhor, nocturno. Nada torna mais evidente o fascínio de desempacotar do que a dificuldade de dar por terminada atarefa. (BENJAMIN, 2009, p. 4-5)

Ao se referir a livros herdados, menciona "a atitude do colecionador em relação às peças que possui", que "vem do sentimento de responsabilidade do dono para com os objectos que possui". Diante da última caixa a ser esvaziada, Benjamin reflete sobre o quanto afluem, neste momento, outros pensamentos, que chama de "imagens, memórias": recordações das cidades em que encontrou seus exemplares, dos seus quartos de quando era criança ou alojamentos de quando era estudante, onde já lhe acompanhavam alguns de seus livros.

Com isso, notamos que Benjamin traz uma defesa apaixonada do ato de se colecionar livros, que na perspectiva do autor corresponde a uma relação subjetiva com os livros, que já pode se iniciar na infância e adolescência. Não se trata de uma defesa de leituras, mas de uma relação com os livros, que dá suporte emocional ao seu colecionador. Somada esta perspectiva à de Montaigne, teremos a seguir a apresentação de como Theodor Adorno, outro expoente da Escola de Frankfurt, como Benjamin, se relacionava com os livros, a partir de um de seus ensaios.

\section{OS LIVROS EM CAPRICHOS BIBLIOGRÁFICOS DE ADORNO}

O ensaio Caprichos Bibliográficos de Adorno se inicia com um lamento do autor: em uma feira de livros, é tomado por uma angústia, sentimento que lhe surge para lhe dizer que "os livros não têm mais aparência de livros" (ADORNO, 1973,p. 17), pois:

A adaptação ao que se consideram com ou sem razão as necessidades dos consumidores, transformou sua fisionomia. As encadernações tornaram-se, internacionalmente, propaganda para o livro. Aquela dignidade do contido em si, 
duradouro, hermético, que capta o leitor dentro de si, fechando sobre ele a tampa como as capas dos livros sobre o texto - isso está afastado como arcaico. O livro insinua-se ao leitor; não surge mais como algo existente por si, e sim por outra coisa, e justamente por isso o leitor se sente privado do melhor. (ADORNO, 1973, p. 17)

A visão crítica de Adorno se encontra no bojo das reflexões do autor sobre a chamada “indústria cultural" (Kulturindustrie), conceito central de seu pensamento (ADORNO, 2002) sobre o qual aqui não nos deteremos ${ }^{4}$. O livro também havia sido transformado em uma mercadoria de massas a ser vendida, e para vendê-lo caberia torná-lo uma propaganda de si, algo que atendesse a consumidores em vez de leitores, saltando aos leitores "com homenzinhos e figurinhas" (ADORNO, 1973, p. 17) ou exagero de formatos, cores etc. Procura-se, com isso, abalar o ser-livro dos livros, para o autor, como algo atrasado e arcaico. O livro torna-se um "bem-de-consumo" e passa a se envergonhar de ainda ser livro em vez de desenho animado ou vitrine iluminada à luz de neon. Esse ensaio é fundamental ao pensarmos no que os livros podem representar como mercadoria, o que "prejudica os livros também como artigo intelectual" (ADORNO, 1973, p. 17).

Adorno tratará também do colecionador de livros, porque "contra a atitude do colecionador pode-se contestar que para ele é mais importante possuir livros do que sua leitura" (ADORNO, 1973, p. 21), o que lhe levará a defender que isso só demonstra que os livros dizem algo, que não é menos importante, mesmo sem que alguém os leia, chegando a citar o provérbio habent sua fata libelli ("os livros têm seu próprio destino"), e por isso os "livros estragados, danificados, que tiveram que sofrer" são os que ele considera "certos": livros que nos acompanham a vida toda e "recusam-se terminantemente à ordem de lugares sistemáticos e insistem naqueles que eles próprios se procuram”. E "quem lhes concede a desordem não tem que lhes ser insensível, mas apenas obediente a seu humor" (ADORNO, 1973, p. 22). Com isso, acaba por fazer uma defesa apaixonada de acervos domésticos de livros, de livros usados e de uma desordem dos livros, atribuindo a eles um "humor".

Esse tipo de figura de linguagem pode servir, por exemplo, para uma defesa junto aos jovens para que comecem a montar seus acervos de livros, inclusive com livros usados que poderão ler (e

\footnotetext{
${ }^{4}$ Não pretendemos realizar um trabalho de exaustiva revisão bibliográfica sobre o pensamento de cada um dos autores tratados no presente artigo, Michel de Montaigne, Walter Benjamin e Theodor Adorno. Nosso intuito foi apenas realizar uma revisão bibliográfica de ensaios que tratam da relação das pessoas com os livros, em diferentes aspectos, optando pela revisão dos três ensaios referidos. Contudo, cada um dos autores possui particularidades de seu pensamento, conceitos centrais em sua obra e notórios intérpretes de seus trabalhos. Para maior detalhamento sobre cada um dos autores e respectivos conceitos, recomendamos a leitura de Starobinski (1992), Kothe (1976) e Jimenez (1977). Este último possui ensaio que aborda fundamentadamente a "indústria cultural", por exemplo, assim como a "obra-de-arte" para Adorno e toda a relação desses conceitos com a teoria estética do sociólogo alemão. Para não se privilegiar Adorno em detrimento de um tratamento mais detido sobre cada um dos autores aqui referidos, nos limitaremos a convidar o leitor a conhecer estas obras de três de seus consagrados intérpretes.
} 
todo livro que ainda não se leu não é um livro novo?), e para que saibam que muitas vezes uma “desordem" entre os livros, em casa, é mais do que usual entre colecionadores de livros.

Adorno reflete sobre o quanto seus livros tinham sido desfigurados com a experiência da emigração da Alemanha, quando foi para os Estados Unidos por conta da perseguição nazista. "Afugentados de suas pacíficas prateleiras, sacudidos, danificados em caixões, acomodados provisoriamente, muitos deles esfacelaram-se" (ADORNO, 1973, p. 22), segundo nos conta, ainda ressalvando que não se livrava dos livros arruinados.

Adorno também se referirá à interiorização, quando alguém que possui um livro o traz em seu encadeamento de ideias. Mas aí também reitera a importância de voltarmos aos livros, pois a memória nos engana e "citações que não são revistas no texto, raramente estão certas" (ADORNO, 1973, p. 23), pois os livros seriam, como os gatos, "animais domésticos brabos": "apresentam-se visíveis e disponíveis como uma posse, mas eles costumam retrair-se” (ADORNO, 1973, p. 23). E observa que, a seu ver, "quem tem contato devido com livros, sente-se dificilmente bem em bibliotecas, apenas razoavelmente na sua”, ainda que os livros que mais se precisa, na própria biblioteca, se recusem aos seus donos, escondendo-se, retornando ao acaso ou não permitindo que se encontre neles uma passagem que se busca, como se fosse uma agulha em um palheiro, como em obras de Marx, Eisler, Kant, Glockner e Hegel, exemplos a que se refere. Para ele, "os livros que são dignos de citar-se levantam permanente protesto contra a citação da qual entretanto não pode prescindir quem escreve sobre livros" (ADORNO, 1973, p. 24).

E Adorno segue sua crítica: contra a técnica do encadernamento que faz os livros sempre se folhearem de um mesmo ponto, contra os títulos impressos ao comprido sobre o dorso (preferindo que o fossem transversalmente), contra a falta do ano e lugar de publicação no frontispício... E dizendo que "sem a melancólica experiência dos livros por fora não seria possível o menor relacionamento com eles, nenhum colecionamento, já nem mesmo a instalação de uma biblioteca" (ADORNO, 1973, p. 27), o autor estabelece o motivo de ponderar tanto sobre a aparência dos livros por fora, como se tal aparência fosse indissociável da experiência que um leitor ou um colecionador terá com um livro. "O destino dos livros tem seu fundamento no fato deles terem caras, e a aflição frente aos que surgem hoje, no fato de que seu semblante começa a lhes ser roubado" (ADORNO, 1973, p. 27).

E então Adorno critica os bibliófilos - aí entendidos como meros colecionadores de livros aos quais os livros são belos se não estão danificados e se conservam-se novos, mesmo quando velhos, em posição com o livro exageradamente burguesa. "O melhor lhe escapa. Sofrimento é a verdadeira beleza nos livros. Sem ele, ela é corrompida em mera cerimônia (...). Quem percebe isto, 
tem uma aversion contra livros não-rompidos; os virgens não proporcionam o menor prazer" (ADORNO, 1973, p. 28), ele diz.

Neste sentido, Adorno praticamente, neste ensaio, defende um manifesto contra um colecionismo como o que vemos se exacerbar na atualidade, em tempos de grandes sites de vendas, em que alguns compradores assíduos de livros querem volumes novos e que deverão permanecer novos mesmo após a leitura. A força da História sobre o aparecimento da encadernação ameaça ultrapassar a espiritualidade das obras, segundo o autor.

Mas aí estará o segredo mais íntimo, para Adorno, da melancolia de livros antigos: "o leitor ideal que eles não suportam saberia certamente, ao sentir a encadernação nas mãos, perceber a figura do frontispício, e a qualidade da configuração das páginas, algo do que está dentro, e perceberia o que ele vale, sem que precisasse ler antes" (ADORNO, 1973, p. 29).

Com isso, vemos uma defesa apaixonada dos livros, por parte de um dos maiores sociólogos, filósofos e críticos literários do Século XX, que pode permitir pensarmos o quanto os livros se relacionam com nossas subjetividades e o quanto podem nos humanizar, ao encontrarmos neles todo o potencial humano de uma redescoberta da humanidade ali contida, fugindo à percepção de que estejamos diante de uma mercadoria saída de uma máquina. Afinal, livros são exemplos muito interessantes do quanto é necessário que pessoas os façam surgir - do autor aos operários da indústria livreira - e, ao mesmo tempo, diante de alguns "caprichos bibliográficos", tão pouco alguém se recorde dessas pessoas ao desejar adquirir uma obra por sua capa ou por sua apresentação.

Trata-se de defesa importante de uma relação apaixonada com os livros e não com os livros que satisfaçam a um critério superficial para colecionadores. Uma lição a ser compartilhada com estudantes desde a educação básica até a Universidade, para que possam compreender os livros como meio de afirmação de nossa humanidade e fonte de nossa humanização, sem que os tratemos como meras mercadorias de encadernação bonita e cheirando a livro novo.

\section{CONSIDERAÇÕES FINAIS}

Neste artigo, apresentamos uma reflexão sobre os livros como objeto de análise e sua relação com nossas subjetividades, partindo do ensaio cético de Montaigne (1533-1592) intitulado Dos Livros (Des Libres), décimo capítulo do segundo livro de Os Ensaios (Les Essais) do final do Século XVI, e alcançando os ensaios críticos intitulados Desempacotando Minha Biblioteca (Ich packe meine Bibliothek aus), da primeira metade do Século XX, publicado em Rua de Mão Única (Einbanhstraße), e Caprichos Bibliográficos (Bibliographische Grillen), da segunda metade do 
Século XX, publicado em Notas de Literatura (Noten zur Literatur), respectivamente de Walter Benjamin (1892-1940) e Theodor Adorno (1903-1969).

Tratou-se de relato de pesquisa empreendida por dois professores da educação básica, em que buscamos por aportes teóricos que refletem uma prática pedagógica de estímulo à relação de nossos alunos com os livros, inclusive no momento da Pandemia de Covid-19 que atravessamos, prática sobre a qual aqui apresentamos fundamentos teóricos.

Pudemos notar que Montaigne faz um elogio à liberdade de pensamento e de julgamento, com a possibilidade dos livros lhe levarem a um autoconhecimento, em um processo de busca permanente de outras interpretações, inquietações e possibilidades. Além disso, defende o conhecimento de diferentes autores e pontos de vista sobre os quais cada coisa se apresenta. Os livros aparecem, assim, não de forma romântica ou sagrada, mas como meio de aquisição de conhecimento e de ampliação da capacidade humana de pensar e de analisar os mais diferentes fenômenos.

Em Benjamin vimos uma defesa apaixonada do ato de se colecionar livros, que na perspectiva do autor corresponde a uma relação subjetiva com os livros, que já pode se iniciar na infância e adolescência. Não se trata de uma defesa de leituras, mas de uma relação com os livros, que dá suporte emocional ao seu colecionador.

Por fim, quase que em uma síntese do pensamento de Montaigne (1984) e de Benjamin (2009), Adorno (1973) nos leva a pensar no quanto os livros se relacionam com nossas subjetividades e o quanto podem nos humanizar, ao encontrarmos neles todo o potencial humano de uma redescoberta da humanidade ali contida, fugindo à percepção de que estejamos diante de uma mercadoria saída de uma máquina. Afinal, livros são exemplos muito interessantes do quanto é necessário que pessoas os façam surgir - do autor aos operários da indústria livreira - e, ao mesmo tempo, diante de alguns "caprichos bibliográficos", tão pouco alguém se recorde dessas pessoas ao desejar adquirir uma obra por sua capa ou por sua apresentação.

Lições a serem, sem dúvida, compartilhadas com estudantes desde a educação básica até a Universidade, para que possam compreender os livros como meio de afirmação de nossa humanidade e fonte de nossa humanização, pelo que trazem (Montaigne, 1984), podem significar a quem venha a possui-los (Benjamin, 2009) ou podem representar criticamente (Adorno, 1973).

\section{REFERÊNCIAS}

ADORNO, T. Caprichos Bibliográficos. In: ADORNO, Theodor. Notas de Literatura. Tradução: Celeste Aída Galeão. São Paulo: Tempo Brasileiro, 1973. 
Paulo: Paz e Terra, 2002.

Indústria Cultural e Sociedade. Tradução: Julia Elisabeth Levy et al. São

BENJAMIN, W. Desempacotando a minha Biblioteca. Tradere. Tradução: João Barrento. Biblioteca Municipal da Póvoa de Varzim, v.1, n.15, p. 1-5, Mai. 2009.

JIMENEZ, M. Para Ler Adorno. Tradução: Roberto Ventura. Rio de Janeiro: Francisco Alves, 1977.

KOTHE, F. Para Ler Benjamin. Rio de Janeiro: Francisco Alves, 1976.

MONTAIGNE, M. Dos Livros. In: MONTAIGNE, Michel. Os Ensaios. Tradução: Sérgio Milliet. São Paulo: Abril Cultural, 1984.

STAROBINSKI, J. Montaigne em Movimento. Tradução: Maria Lúcia Machado. São Paulo: Companhia das Letras, 1992. 